\title{
Approach to Patients with Malignant Melanoma of Unknown Primary Origin
}

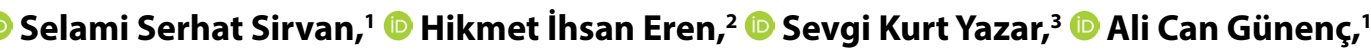

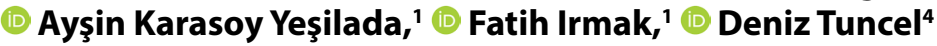

'Department of Plastic Reconstructive and Aesthetic Surgery, Health Sciences University Sisli Hamidiye Etfal Training and Research Hospital, Istanbul, Turkey

${ }^{2}$ Department of Plastic Reconstructive and Aesthetic Surgery, Hatay State Hospital, Hatay, Turkey

${ }^{3}$ Department of Plastic Reconstructive and Aesthetic Surgery, Health Sciences University Istanbul Training and Research Hospital, Istanbul, Turkey

${ }^{4}$ Department of Pathology, Sisli Hamidiye Etfal Training and Research Hospital, Istanbul, Turkey

\begin{abstract}
Objectives: Although malignant melanoma accounts for $3 \%$ of skin cancers, it is responsible for $75 \%$ of deaths associated with skin cancer. In our study, all melanoma cases diagnosed and treated at our clinic were retrospectively reviewed, and the cases of unknown primary origin among them were examined in detail in terms of diagnosis and treatment.

Methods: The patients with malignant melanoma treated at the inpatient services of our clinic between January 1991 and April 2017 were retrospectively screened in the records. These patients were evaluated for age, sex, tumor type, Breslow depth, metastasis, and treatment. Among these patients, four cases of unknown primary origin were examined in detail.

Results: During January 1991 and April 2017, 173 patients received inpatient care for malignant melanoma at our clinic. As regards to the melanoma subtypes, nodular type in 45 patients, acral lentiginous type in 43 patients, superficial spreading type in 63 patients, lentigo maligna melanoma in 15 patients, subungual type in 7 patients, and either unidentified melanoma or other subtypes in 10 patients were identified.

Conclusion: The ideal treatment of a patient with melanoma is multidisciplinary, with plastic surgery having a central role. Keywords: Melanoma; metastasis; skin cancer.

Please cite this article as "Sirvan SS, Eren HI, Kurt Yazar S, Günenç AC, Karasoy Yeşilada A, Irmak F, et al. Approach to Patients with Malignant Melanoma of Unknown Primary Origin. Med Bull Sisli Etfal Hosp 2019;53(2):125-131." Ithough malignant melanoma (MM) accounts for $3 \%$ of skin cancers, it is responsible for $75 \%$ of deaths associated with skin cancer. ${ }^{[1]}$ Melanoma incidence has been considerably rising during the past three decades. ${ }^{[2]}$ The lifelong possibility to develop melanoma is $1 / 40$ in males and $1 / 60$ in females. ${ }^{[3]}$ In regards to diagnosis, treatment, and management of melanoma, some of the detailed issues could demonstrate variabilities, rendering the condi-

tion complicated. ${ }^{[4]}$ Although more than $95 \%$ of cases of melanoma originate from skin, some melanoma cases of unknown primary origin involving lymph nodes or visceral organs without any foci on the skin may be observed..$^{[5]}$ In our study, all melanoma cases diagnosed and treated at our clinic were retrospectively reviewed, and the cases of unknown primary origin among them were examined in detail in terms of diagnosis and treatment.
\end{abstract}

A

Address for correspondence: Hikmet İhsan Eren, MD. Hatay Devlet Hastanesi, Plastik Rekonstrüktif ve Estetik Cerrahi Anabilim Dalı, Hatay, Turkey Phone: +90 5532157763 E-mail: hikmetihsaneren@gmail.com

Submitted Date: December 25, 2018 Accepted Date: January 28, 2019 Available Online Date: March 22, 2019

${ }^{\circ}$ Copyright 2019 by The Medical Bulletin of Sisli Etfal Hospital - Available online at www.sislietfaltip.org

OPEN ACCESS This is an open access article under the CC BY-NC license (http://creativecommons.org/licenses/by-nc/4.0/) 


\section{Methods}

The patients with MM treated at the inpatient services of our clinic between January 1991 and April 2017 were retrospectively screened in the records. These patients were evaluated for age, sex, tumor type, Breslow depth, metastasis, and treatment. Among these patients, four cases of unknown primary origin were examined in detail.

\section{Results}

Between January 1991 and April 2017, 173 patients (92 males and 81 females) received inpatient care for $M M$ at our clinic. The age of the patients ranged between 2 and 82 years, and the mean age was 52.56 years. A mass was detected in the head and neck region of 48 patients, on lower extremities of 69 patients, on the trunk of 29 patients, on upper extremities of 18 patients, and in the genital area of 7 patients (Fig. 1). As regards to the melanoma subtypes, nodular type in 45 patients, acral lentiginous type in 43 patients, superficial spreading type in 63 patients, lentigo maligna melanoma in 15 patients, subungual type in 7 patients, and either unidentified melanoma or other subtypes in 10 patients were identified. Breslow value was measured 0-1 $\mathrm{mm}$ in 19 patients, $1-2 \mathrm{~mm}$ in 35 patients, $2-4 \mathrm{~mm}$ in 68 patients, and deeper than $4 \mathrm{~mm}$ in 39 patients; while in 12 patients, Breslow depth could not be evaluated. Sentinel lymph node sampling in 51 patients, axillary lymph node sampling in 26 patients, inguinal lymph node sampling in 57 patients, and lymph node sampling at neck area

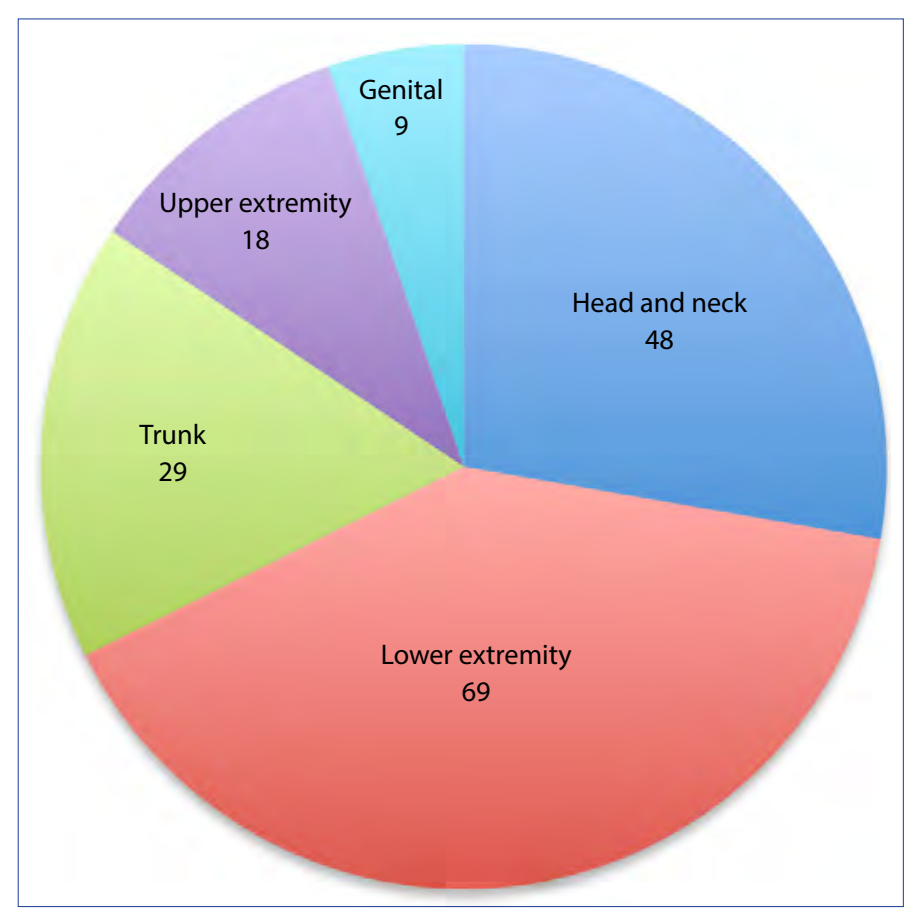

Figure 1. Anatomic localizations of melanoma. in 25 patients were performed, comprising a total of 108 regional lymph node dissection cases. With regard to the defects developed after tumor resection, primary suturing in 11 patients, partial or complete digital amputation in 12 patients, local or distant flaps in 41 patients, and partial or full thickness grafts in 119 patients were performed for reconstruction. Contacting patients or their relatives revealed that of 124 patients, 47 died, 75 lived uneventfully, and 2 were in the terminal period.

\section{Case Reports}

Case 1 - A 52-year-old male patient presenting with the complaints of vomiting, weight loss, and abdominal pain received treatment at a health center; but as the complaints continued, he underwent abdominal ultrasonography revealing intestinal thickening. Then, a contrasted intestinal scopy was performed demonstrating a mass of $7.5 \mathrm{~cm} \times 2.5$ $\mathrm{cm}$ in size. Following this finding, the patient underwent a segmental resection of the small bowel. As the pathological examination determined metastasis of melanoma, the patient was referred to the oncology department at our hospital. To screen for the primary focus postoperatively, gastroenterology, ophthalmology, dermatology, and ENT (ear, nose, throat) consultations were received together with endoscopy and colonoscopy examinations of the gastrointestinal system. However, a primary focus was not identified. During the postoperative follow-up period, an intramuscular metastatic lesion of $12 \mathrm{~mm} \times 6 \mathrm{~mm} \times 6 \mathrm{~mm}$ in size adjacent to biceps femoris muscle in the posterior part of the left lower extremity was detected in the whole body PET CT. Due to this finding, primarily an excisional biopsy of the mass was performed. As the pathological examination result was metastasis of melanoma, the patient had received a temodal treatment for 9 months. During the follow-up period, a mass was identified on the medial side of the right knee joint. Following an incisional biopsy revealing melanoma metastasis, left inguinal sentinel sampling and left popliteal dissection were performed (Fig. 2). As metastasis in the inguinal and popliteal regions was reported as the result of the pathological examination, the patient underwent additional inguinal dissection. The oncology team provided the limb perfusion treatment to the patient. The patient was monitored at the follow-up visits; however, he died in the fifth year following the diagnosis.

Case 2 - A 29-year-old male patient presenting with a groin mass in the inguinal region for one year started antibiotic therapy at a health-care center. As there was no regression in the mass, an excisional biopsy was performed. The patient presented to our outpatient clinics with the biopsy result reporting metastasis of MM. A PET CT was performed, and the pathology specimens were re-evaluated at our hospital. In 


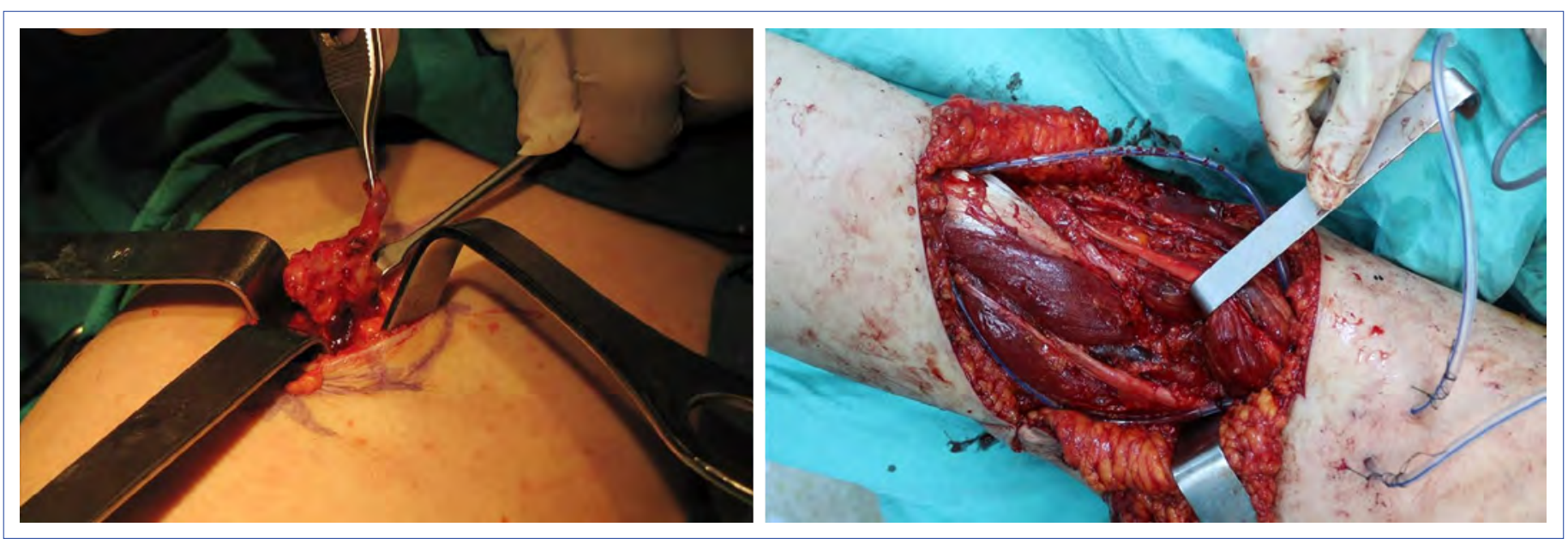

Figure 2. Left inguinal sentinel sampling and left popliteal dissection.

addition, the patient was consulted by the dermatology clinic preoperatively for his additional skin lesions. No additional focus was identified, and the patient underwent inguinal curettage. To screen for the primary focus postoperatively, gastroenterology, ophthalmology, dermatology, and ENT consultations were received together with endoscopy and colonoscopy examinations of the gastrointestinal system. However, the primary focus was not detected. The oncology team gave interleukin treatment to the patient, and he has continued his follow-up visits at our clinic.

Case 3 - A 49-year-old female patient presenting with a mass in the left inguinal region for 2 years was followed up on medical treatment at a health-care center for 6 months. As there was no relief in her complaints, she was referred to another facility. Following an excisional biopsy, the patient was referred to our clinic with the biopsy result reporting melanoma infiltration. A PET CT was performed, and the patient was consulted by the dermatology clinic preoperatively for his additional skin lesions. Both examinations resulted in no evidence of any other foci. Then, an inguinal lymph node dissection was performed. To screen for the primary focus postoperatively, gastroenterology, ophthalmology, dermatology, and ENT consultations were received together with endoscopy and colonoscopy examinations of the gastrointestinal system. However, a primary focus was not detected. Because a BRAF mutation was detected, the oncology team gave vemurafenib treatment to the patient. She has been followed up at the oncology clinic and at our facilities.

Case 4 - A 46-year-old male patient presenting with a hypertrophic lesion in the heel was administered cryotherapy at a dermatology clinic. As there was no relief in his complaints, a punch biopsy was performed reporting a melanoma infiltration. Then, the patient was referred to our clinic. A PET CT was performed, and the patient was consulted by the dermatology clinic preoperatively for his additional skin lesions. The lesion in the heel was excised within adequate surgical margins, and then was repaired by a vastus lateralis free flap. (Although ALT was initially planned, the vastus lateralis muscular flap was performed as the patient's skin perforators were not sufficient; Fig. 3.)

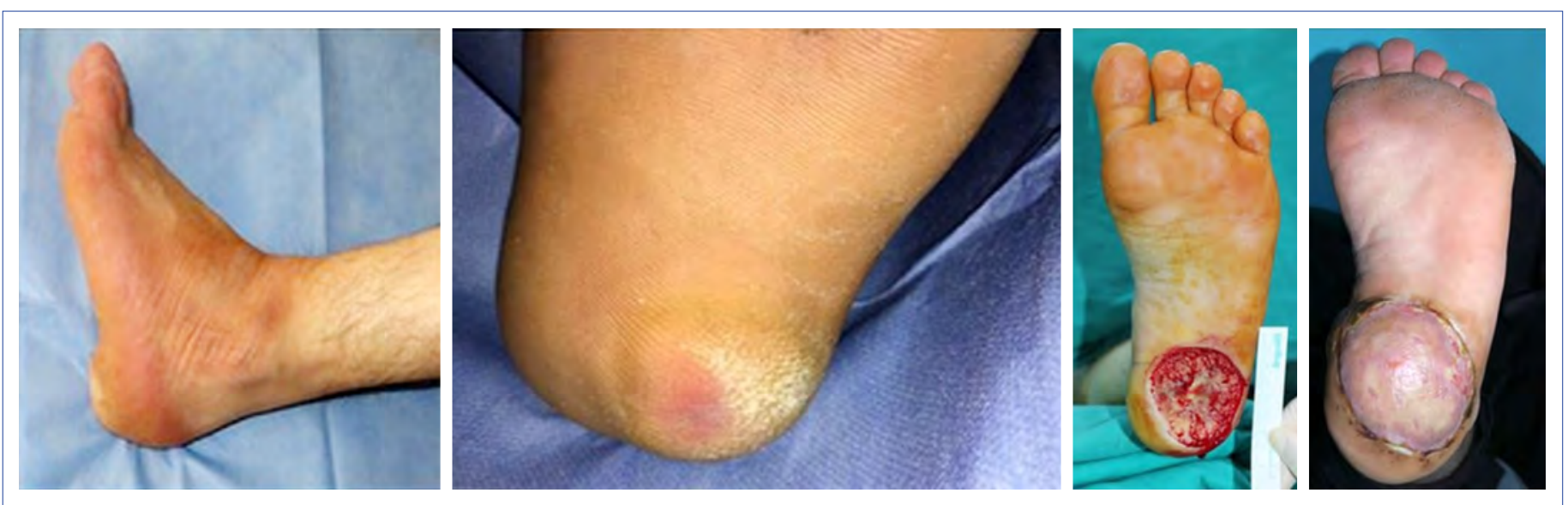

Figure 3. Lesion in the heel was excised within adequate surgical margins, and then was repaired by a vastus lateralis free flap. 
The pathological examination reported an infiltration of MM (Figs. 4 a-d). To screen for the primary focus postoperatively, gastroenterology, ophthalmology, dermatology, and ENT consultations were received together with endoscopy and colonoscopy examinations of the gastrointestinal system. But a primary focus was not evident.

Four patients with melanoma metastasis because of pathology were investigated in terms of finding the primary lesion (Flowchart); however, the primary focus could not be determined. These patients were examined in detail in terms of diagnosis and treatment (Fig. 5).

\section{Discussion}

MM originates from melanocytes, a subtype of the dendritic cells or from nevus cells in the basal layer of the skin. Me- lanocyte cells not only are limited to the skin, but may be present in the eyes, upper respiratory tract, gastrointestinal tract, normal lymph node capsules, and central nervous system. Therefore, a primary melanoma can originate from these sites. ${ }^{[5]}$ More than $95 \%$ of MM cases are observed in the skin covering the body. Cutaneous melanoma has a rising incidence in the Caucasian population, and is responsible for $75 \%$ of deaths from skin cancer ${ }^{[6]} \mathrm{MM}$ comprises $1.5 \%$ of all cancers and $1 \%$ of cancer-related deaths. ${ }^{[7]}$ The incidence of $\mathrm{MM}$ in the Caucasian population has increased three times in the past 20 years. ${ }^{[8]}$ Twenty years ago, its lifetime prevalence was $1 / 150$ in males and $1 / 600$ in females; however, these rates are $1 / 37$ for males and $1 / 56$ in females at present. ${ }^{[9]}$

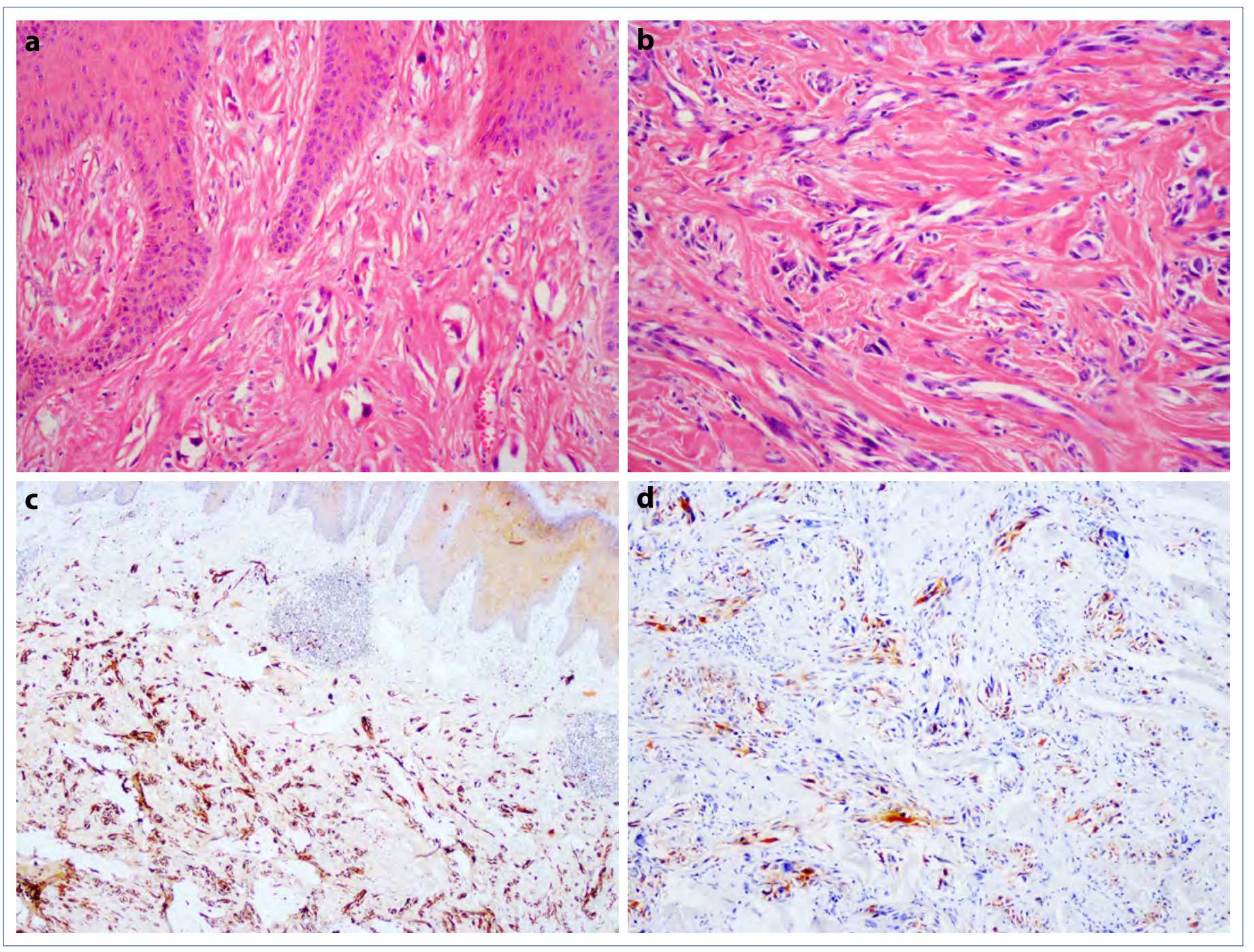

Figure 4. (a) Melanocytes with prominent nucleus and nucleoli and condensed chromatin arranged in nests and individually in the sclerotic dermis with no continuity with the overlying epidermis. $\mathrm{H} \& \mathrm{E}, \mathrm{x} 200$. (b) Melanocytes with prominent nucleus and nucleoli and condensed chromatin arranged in nests and individually in the sclerotic dermis, H\&E, x400. (c) Melanocytes strongly stained with HMB45 within the sclerotic dermis. Note that the stratified squamous epithelium is unremarkable. HMB-45 stain, $x 100$. (d) Weakly positive stained melanocytes with Melan A within the sclerotic dermis. Melan A, x200. 
Question the exclusion criteria of Das Gupta

No Primary

Review retrospective excision materials if possible

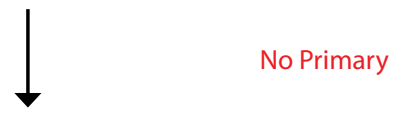

- Whole-body dermatological exarmination

- Gastrointestinal system endoscopy

- Ear ophthalmoscopic examination

- Detailed physical examination including the anus and genital area

- Gynecological examination in female patients

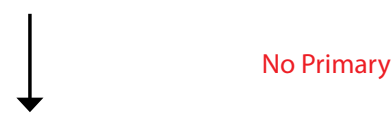

Computerized tomography for the brain, neck, thorax and abdominal region or whole body pet ct

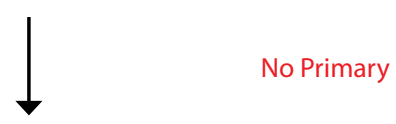

Unknown Primary Melanoma

Figure 5. Flowchart to approach of primary unknown malignant melanoma.

Widespread metastases are the main cause of death in patients with MM. Melanoma metastases are observed in local lymph nodes, or develop as satellite or in transit lesions, or become evident as distant organ metastasis. ${ }^{[10]} A$ study conducted at the University of Tuebien retrospectively reviewed melanoma cases in a 20 -year period, and reported metastases in 466 of 3001 patients. A total of $50 \%$ of the metastases were detected in the lymph nodes, $22 \%$ of them were satellite or in transit metastases, and $28 \%$ of them were distant organ metastases including distant metastases in skin. ${ }^{[11]}$ In our clinic, among 173 patients, regional lymph node, satellite, and in transit metastases were evident in 34, 3, and 2 patients respectively. When distant metastases of primary melanomas were evaluated, cutaneous melanomas were identified to develop distant metastases to lung most commonly. ${ }^{[12]}$ The influencing factors in melanoma metastasis are the region of the primary tumor most commonly, followed by the gender and age of the patient, histology findings, tumor depth, and the extent of invasion. Satellite or in transit metastasis rates are higher in lesions of the extremities and trunk. However, all three ways of metastasis are observed with the melanomas in head and neck. ${ }^{[10]}$ In regards to tumor thickness, values lower than $0.76 \mathrm{~mm}$ and over $1.5 \mathrm{~mm}$ are associated with higher rates of satellite and in transit metastases, and thickness values between 0.75 and $1.5 \mathrm{~mm}$ are related with higher rates of distant metastases. ${ }^{[10]}$ When the timing of metastasis is evaluated, it requires a mean of 25 months for distant metastases, a mean of 17 months for satellite or in transit metastases, and a mean of 16 months for lymph node metastases. ${ }^{[13]}$

Pack in 1952 identified MM of unknown primary origin or otherwise called occult melanoma in a patient with a diagnosis of subcutaneous, nodal, or visceral metastatic melanoma without an identified cutaneous, ocular, or mucosal primary origin, and who had no history of histological examinations or excisions. ${ }^{[14]}$ Melanoma of an unknown primary origin is usually diagnosed when clinical symptoms due to metastasis become evident. In 1963, Das Gupta defined the exclusion criteria in the differential diagnosis of $M M .{ }^{[15]}$ According to these criteria, the patients should be excluded from the differential diagnosis if they have a history of previous orbital exenteration or enucleation, if there is a history of excision, electrodessication, or cauterization rendering a retrospective pathological examination inadequate, and if patients with lymph node metastases have scars in the region where drainage occurred, and if they are evaluated neither by a detailed physical examination including anus and genital area nor by ophthalmoscopy.

Several theories have been proposed for the development of melanoma of an unknown origin. These theories provided the following explanations including the regression associated with immune response following metastasis of the primary tumor, ${ }^{[16]}$ melanoma developing in nevus cells of lymph nodes, metastasis of an undetected tumor in the body, misdiagnosis of the previous excision material, and presence of a primary tumor in an unusual or shrouded region. ${ }^{[17]}$ The most commonly recognized theory is the regression of the primary lesion due to stimulation of immune system.

The study by Kamposiras et al. ${ }^{[18]}$ reviewed all melanoma cases published in literature till 2010, and reported melanoma of unknown primary origin in 4348 of 136.991 patients with melanoma. According to this study, the incidence of melanoma of unknown primary origin was determined as $3.2 \%$. In this study, the period before 1980 , which is the year when $\mathrm{CT}$ was implemented into practice, and the period after $\mathrm{CT}$ implementation were compared demonstrating incidences of $5.05 \%$ and $2.7 \%$ for the pre-CT and post-CT periods respectively. The same study reported the ratio of male patients to female patients as 2/1 (2948/1454). Savoia 
et al. ${ }^{[19]}$ reported 88 patients with melanoma of unknown origin in their 33-year study with a series of 4481 patients with melanoma. Of these 88 patients, metastases were detected in skin and subcutaneous tissue in 31 patients, in the lymph nodes in 48 patients, and in visceral organs in 15 patients. The rate of melanoma of unknown origin of our clinic is $0.02 \%$ with one patient having a visceral metastasis, two patients with lymph node metastases, and one patient with a metastasis in lower extremity.

For patients with melanoma of unknown origin, to identify the primary lesion, it is recommended that all previous excision materials should be examined in detail for melanoma in first place; gastrointestinal endoscopy, endoscopic examination of nose and larynx, otoscopy, ophthalmoscopy, and a detailed physical examination including anus and genital area should be performed; female patients should be gynecologically examined; and CT scans of brain, neck, thorax, and abdomen must be obtained. ${ }^{[20]} \mathrm{A}$ Wood lamp examination by UV light is warranted in cases with depigmented halo nevi and scars or in cases when a regressed melanoma is suspected. ${ }^{[21]}$ To screen for the primary origin, all patients in our study were consulted with gastroenterology, ophthalmology, dermatology, and ENT postoperatively, and endoscopic and colonoscopic examination of GIS were provided; however, no primary foci were evident. The female patient was consulted with the gynecology department additionally.

Initial treatment of patients with melanoma of unknown origin is surgery. Palliative or adjuvant treatment is administered in alignment with the planning made according to patients' condition postoperatively. The medicines used for this treatment include interferon alpha $2 \mathrm{~b}, \mathrm{IL}-2$, dacarbazine, temozolomide, BOLD regime (bleomycin, vincristine, lomustine, and dacarbazine). ${ }^{[18]}$

The survival is more favorable in patients with melanoma of unknown origin. These cases are considered to be associated with an increased immune response to the metastatic lesion in return for the immune response so strong to regress the primary tumor. ${ }^{[22]}$ The literature review by Kamposiras et al. ${ }^{[18]}$ recognizes that for nodal metastasis of unknown primary origin, the mean survival is between 24 and 165 months, whereas in visceral metastasis it is between 3 and 13.2 months. In addition, it is reported that in nodal metastasis 10-year survival rate is between $18.8 \%$ and 62.9\%; however, in visceral metastasis, no patients with a 10-year survival are evident.

\section{Conclusion}

Unknown primary melanoma are challenging for both surgeons and oncologist. Standard guidelines are not avail- able because of its rarity. ${ }^{[23]}$ Case series are important in terms of guiding the physicians in the absence of these guidelines. ${ }^{[24]}$ Cooperative studies involving several treatment center are critical in these kind of rare tumors. Combination of these information can provide larger number of cases for better decision making. ${ }^{[25]}$

\section{Disclosures}

Ethics Committee Approval: The study was approved by the Sisli Hamidiye Etfal Training and Research Hospital Ethics Committee in 2016.

Peer-review: Externally peer-reviewed.

Conflict of Interest: None declared.

Authorship Contributions: Concept - S.S.S., H.I.E.; Design S.S.S., H.I.E.; Supervision - S.K.Y., A.K.Y.; Materials - A.C.G., F.I.; Data collection \&/or processing - H.I.E., A.C.G.; Analysis and/or interpretation - S.S.S., H.I.E.; Literature search - S.S.S., H.I.E.; Writing S.S.S., H.I.E.; Critical review - A.K.Y.

\section{References}

1. Dzwierzynski WW. Managing malignant melanoma. Plast Reconstr Surg 2013;132:446e-60e. [CrossRef]

2. Lasithiotakis KG, Leiter $\mathrm{U}$, Gorkievicz R, Eigentler T, Breuninger $\mathrm{H}_{\text {, }}$ Metzler $\mathrm{G}$, et al. The incidence and mortality of cutaneous melanoma in Southern Germany: trends by anatomic site and pathologic characteristics, 1976 to 2003. Cancer 2006;107:1331-9.

3. Jemal A, Siegel R, Ward E, Hao Y, Xu J, Murray T, et al. Cancer statistics, 2008. CA Cancer J Clin 2008;58:71-96. [CrossRef]

4. Pavri SN, Clune J, Ariyan S, Narayan D. Malignant Melanoma: Beyond the Basics. Plast Reconstr Surg 2016;138:330e-40e. [CrossRef]

5. Skarbez K, Fanciullo L. Metastatic melanoma from unknown primary presenting as dorsal midbrain syndrome. Optom Vis Sci 2012;89:e112-7. [CrossRef]

6. Jaukovic L, Sijan G, Rajović M, Kandolf-Sekulovic L, Radulovic M, Mijuskovic Z, et al. Lymphoscintigraphy and sentinel lymph node biopsy, in cutaneous melanoma staging and treatment decisions. Hell J Nucl Med 2015;18:146-51.

7. Karasoy AK, Irmak F, Sevim KZ, et al. The case of malignant melanoma with extensive local recurrence and in-transit metastasis in the lower extremity. Turk Plast Surg 2012:3:39-42

8. Jemal A, Siegel R, Xu J, Ward E. Cancer statistics, 2010. CA Cancer J Clin 2010;60:277-300. [CrossRef]

9. Edwards BK, Brown ML, Wingo PA, Howe HL, Ward E, Ries LA, et al. Annual report to the nation on the status of cancer, 1975-2002, featuring population-based trends in cancer treatment. J Natl Cancer Inst 2005;97:1407-27. [CrossRef]

10. Zbytek B, Carlson JA, Granese J, Ross J, Mihm MC Jr, Slominski A. Current concepts of metastasis in melanoma. Expert Rev Dermatol 2008;3:569-85. [CrossRef]

11. Meier F, Will S, Ellwanger U, Schlagenhauff B, Schittek B, Rassner $G$, et al. Metastatic pathways and time courses in the orderly pro- 
gression of cutaneous melanoma. Br J Dermatol 2002;147:62-70.

12. Abeloff, MD. Clinical Oncology. 3rd ed. PA, Elsevier Churchill Livingstone; 2004.

13. Soong SJ, Harrison RA, McCarthy WH, Urist MM, Balch CM. Factors affecting survival following local, regional, or distant recurrence from localized melanoma. J Surg Oncol 1998;67:228-33. [CrossRef]

14. Pack GT, Gerber DM, Scharnagel IM. End results in the treatment of malignant melanoma; a report of 1190 cases. Ann Surg 1952;136:905-11. [CrossRef]

15. Dasgupta T, Bowden L, Berg JW. Malignant Melanoma of Unknown Primary Origin. Surg Gynecol Obstet 1963;117:341-5.

16. Anbari KK, Schuchter LM, Bucky LP, Mick R, Synnestvedt M, Guerry D 4th, et al. Melanoma of unknown primary site: presentation, treatment, and prognosis--a single institution study. University of Pennsylvania Pigmented Lesion Study Group. Cancer 1997;79:1816-21. [CrossRef]

17. Dutton-Regester K, Kakavand H, Aoude LG, Stark MS, Gartside $M G$, Johansson $P$, et al. Melanomas of unknown primary have a mutation profile consistent with cutaneous sun-exposed melanoma. Pigment Cell Melanoma Res 2013;26:852-60. [CrossRef]

18. Kamposioras K, Pentheroudakis G, Pectasides D, Pavlidis N. Malignant melanoma of unknown primary site. To make the long story short. A systematic review of the literature. Crit Rev Oncol Hema- tol 2011;78:112-26. [CrossRef]

19. Savoia P, Fava P, Osella-Abate $S$, Nardò T, Comessatti A, Quaglino $P$, et al. Melanoma of unknown primary site: a 33-year experience at the Turin Melanoma Centre. Melanoma Res 2010;20:227-32. [CrossRef]

20. O'Neill JK, Khundar R, Knowles L, Scott-Young N, Orlando A. Melanoma with an unknown primary--a case series. J Plast Reconstr Aesthet Surg 2010;63:2071-80. [CrossRef]

21. Serna MJ, Vázquez-Doval J, Sola MA, Ruiz de Erenchun F, Quintanilla E. Metastatic melanoma of unknown primary tumor. Cutis 1994;53:305-8.

22. Lee CC, Faries MB, Wanek LA, Morton DL. Improved survival for stage IV melanoma from an unknown primary site. J Clin Oncol 2009;27:3489-95. [CrossRef]

23. Sirvan SS, Akgun I, Sevim KZ, Dağdelen D, Yenici O, Yeşilada $A K$, et al. Sentinel lymph node biopsy for skin tumors. SETB 2016;50:220-7. [CrossRef]

24. Karasoy A, Karşıdağ S, Tatlıdede S, Uğurlu K, Özkaya Ö, Kuran İ, et al. Our experience for 65 patients with malignant melanoma in 13 years : A retrospective study. Türk Plast Rekonstr Est Cerrahi Derg 2004; 12:153-57.

25. Aydemir EH. Malignant Melanoma Treatment by stage. Türkderm 2007;41:20-1. 